\title{
O ATO DE LER E DE ESCREVER NA CONSTRUÇÃO DO PROJETO DE PESQUISA CIENTÍFICA: UMA EXPERIÊNCIA EM SALA DE AULA
}

\author{
Maria Sandra Montenegro Silva Leão ${ }^{1}$
}

\begin{abstract}
Resumo
Leitura e escrita no período acadêmico são ações interligadas, mas, percebidas pela maioria dos estudantes de Pedagogia, matriculados no componente Trabalho de Conclusão de Curso, como algo complexo. O problema se revela desde a vivência da disciplina Metodologia da Pesquisa Educacional. Nesta direção, trazemos um relato de uma experiência com estudantes de TCC com dificuldades em organizar conhecimentos necessários para a elaboração do projeto de pesquisa. A experiência se norteou pela teoria de Paulo Freire, demonstrando a possibilidade de vencer parte dessas dificuldades quando os estudantes compreendem o ler e o escrever como construção ativa, como instrumentos pedagógico e político.
\end{abstract}

Palavras-chave Ler. Escrever. Projeto de Pesquisa.

\begin{abstract}
Reading and writing during the courses of the graduation are interconnected actions, therefore, perceived by most of the students of Pedagogy, in the component Course's Conclusion like a something complex act. The problem is revealed since the experience of the discipline Methodology of Educational Research. In this direction, we bring an account of an experience with students has been difficulties in organizing knowledge necessary for the elaboration of the research project. The experience was guided by Paulo Freire's theory, demonstrating the possibility of overcoming some of these difficulties when students understanding that reading and writing as an active construction and at the same time it is a pedagogical and political instruments.
\end{abstract}

Keywords Reading. Writing. Research Project.

\section{INTRODUÇÃO}

O objetivo deste artigo é apresentar os resultados de uma experiência de sala de aula, com estudantes da disciplina Trabalho de Conclusão de Curso I, no ano de 2015, tendo sido utilizado estratégias diversas, mas fundamentalmente amparamos nosso trabalho a partir da leitura e estudo dos livros "A importância do ato de ler" e "Educação e Mudança", da autoria de Paulo Freire, assim como, tomando como ponto de partida a escuta em relação as dificuldades expressas no conteúdo verbal e no conteúdo escrito de alguns estudantes em

\footnotetext{
${ }^{1}$ ) Professora adjunta do Departamento de Administração Escolar e Planejamento Educacional, da UFPE. Email: sandra.montenegro@uol.com.br
}

Revista de Administração Educacional, Recife, V. 1 . No 1 . 2017 jan./jun. 2017 p.99-113 
nossa sala de aula. É lugar comum, em quase todos os semestres que trabalhamos com a citada disciplina, constatarmos sintomas ${ }^{2}$ reveladores dos problemas de aprendizagem apresentados pelos estudantes em nossa sala de aula, dentre os quais, insegurança de alguns estudantes em torno da sua produção acadêmica, propiciada pelo trabalho de conclusão de curso, timidez para expressar dúvidas coletivamente, falar em um tom de voz muito baixo, quase não desejando ser escutado ou procurar a professora ao término da aula para tirar dúvidas, quando poderia tê-lo feito no momento em que a aula transcorria.

O temor do fracasso ficava evidente diante das exigências da academia quanto ao volume de leituras e a dificuldade para acompanhar as solicitações docentes com profundidade de capacidade crítica e de escrita argumentativa. Assim expressaram diversos estudantes quando abordamos as dificuldades que estavam sentindo.

É uma situação difícil não somente para estudantes, mas afeta parte do trabalho docente, principalmente para aqueles que têm o propósito de contribuir com uma excelente formação acadêmica, profissional e humana de nossos estudantes. De uma maneira geral, é possível identificar as dificuldades dos alunos para fazerem uma aplicação social da leitura, interpretar de maneira argumentativa o que se lê e construir elos, sentidos com o real da educação em suas diversas complexidades. Isto não acontece apenas pela suposta dificuldade dos textos acadêmicos. A origem desta situação pode ser encontrada em diversos fatores: um baixo consumo de livros durante a educação básica, os modos que a qualidade da leitura analítico-interpretativa foi realizada durante o processo de formação inicial, baixo acesso as bibliotecas públicas, portanto, pouco incentivo para leitura e escrita em diversas ordens. Considerando, ainda, que temos um público de estudantes que trabalham durante o dia e quase não dispõem de tempo para a realização de leituras interpretativas com a qualidade desejada pela academia.

A partir desta constatação desenvolvemos a prática, no início da disciplina, de aprendermos dialogando sobre o significado da leitura crítica para a formação profissional, política, humana e para o desenvolvimento da pesquisa científica. Conforme Freire (1989), ler e escrever não se excluem, não existe dicotomia nessas duas dimensões, todavia é uma ação que exige 'disciplina intelectual' devido a sua complexidade.

\footnotetext{
2 ) Sintoma é um conflito psíquico, gerador de diversos mal-estares e aponta para uma pulsão de destruição que age de maneira inconsciente no indivíduo.
}

Revista de Administração Educacional, Recife, V. 1 . No 1 . 2017 jan./jun. 2017 p.99-113 
A problemática trazida pelos estudantes revelou um sentimento de insegurança para a escrita acadêmica e dificuldades para ultrapassar o pensamento senso-comum. Apresentavam baixa autoconfiança para expressar o pensamento através da escrita, compor um texto com autoria e opinar publicamente.

A partir dos problemas identificados, elaboramos uma proposta de trabalho, socializamos a mesma com o grande grupo e em seguida experimentamos contribuir com o percurso de formação, considerando a importância dos estudantes de se sentirem seguros para a escrita acadêmica do projeto do Trabalho de Conclusão de Curso, que, em nossa perspectiva, ajuda na autoestima e os encoraja para se lançarem com mais ousadia em outros projetos profissionais e pessoais. Ressaltamos que este texto não é resultado de uma pesquisa científica, mas de uma prática em sala de aula, que teve por intenção compreender as dificuldades dos estudantes em relação a disciplina, e a partir da palavra manifestada por eles, intervir na realidade e ajudar na solução da questão em tela.

\section{IDENTIFICANDO AS DIFICULDADES: OS DIZERES DOS ESTUDANTES}

Para a realização deste trabalho foi solicitado aos estudantes da disciplina Trabalho de Conclusão de Curso, o registro de suas dificuldades relativas as questões que consideravam mais graves. Foram relevantes a problemática da leitura interpretativa e da escrita acadêmica. Dos 25 estudantes, apenas 06 disseram que não sentiam problemas dessa ordem, mas quiseram participar da atividade. Os que não sentiam dificuldades participaram da experiência contribuindo para ajudar nas reflexões, completarem ideias, apresentarem exemplos, dentre outras ações. Os 19 estudantes que não se sentiam seguros para a crítica, a reflexão e a escrita acadêmica expressaram as seguintes dificuldades: 
Quadro 01 - Dificuldades de leitura e escrita na academia

\begin{tabular}{|c|c|}
\hline Quantidade de estudantes & \begin{tabular}{c} 
Dificuldades comuns \\
\hline 08
\end{tabular} \\
\hline 05 & $\begin{array}{c}\text { Vocabulário difícil em muitos textos durante o curso e não se } \\
\text { sentiam motivados para consultar dicionários. Preferiam } \\
\text { buscar entender o contexto da frase, mas nem sempre } \\
\text { conseguiam }\end{array}$ \\
\hline 06 & $\begin{array}{l}\text { Textos sem articulação com questões mais práticas da vida, } \\
\text { como articular o que estudavam com um possível problema } \\
\text { para o projeto de pesquisa. }\end{array}$ \\
\hline $\begin{array}{l}\text { Pouca escrita individual durante o curso. A escrita } \\
\text { predominante é realizada com trabalhos em grupo ou provas } \\
\text { individuais, mas de pouco uso dos textos. A construção de } \\
\text { artigos é pouca, baixo incentivo à produção escrita. } \\
\text { Dificuldades para escrever criticamente. Resumir é entendida } \\
\text { como uma atividade mais fácil. }\end{array}$ \\
\hline 19
\end{tabular}

fonte: da própria autora

Ressaltamos que o nível socioeconômico predominante do grupo é de baixo poder aquisitivo, todos estavam empregados, mas contribuíam com as despesas domésticas. Dos dezenove participantes com problemas na aprendizagem da disciplina, cinco são casados e com filhos. Em suas falas, o ambiente doméstico não os ajudava na concentração dos estudos. Grande parte do grupo vem de famílias grandes (mais de cinco pessoas no núcleo familiar).

Em seguida, perguntamos ao grupo o que é pesquisa científica e para que serve? Dois estudantes afirmaram que "pesquisar é saber conhecer a realidade" e outro estudante entende que pesquisar "serve para descobrir coisas que desconhecemos". Os demais estudantes concordaram com estas percepções, mas acrescentaram ideias que nos remete a 
mitos que dificultam a arte de pesquisar. Por exemplo: "pesquisar é para quem nasce com essa vocação", ou "pesquisar é algo muito nebuloso, não é para simples mortais" (a turma riu), e ainda, "pesquisar serve para resolver coisas do dia-a-dia", o que não deixa de ser verdade, porém, não era a este tipo de pesquisa que estávamos desejando abordar. Observamos que em diversos momentos havia respostas distantes do que foi perguntado, o que expressa fragilidade em se focalizar na questão e não responder por impulso.

Apesar de todos terem cursado a disciplina Metodologia da Pesquisa Educacional, ninguém lembrou que pesquisa científica é um processo rigoroso, metódico, sistemático, crítico, empírico e tem a finalidade de produzir conhecimentos e teorias, ou resolver problemas (pesquisa aplicada).

Conforme Sampieri (2004, p. 22):

A pesquisa científica é entendida como um conjunto de processos sistemáticos e empíricos utilizado para o estudo de um fenômeno; é dinâmica, mutável e evolutiva. Pode se apresentar de três formas: quantitativa, qualitativa e mista. Esta última implica combinar as duas primeiras. Cada uma é importante, valiosa e deve ser respeitada da mesma maneira.

Percebemos que as dificuldades não se restringiam apenas a leitura, escrita e análise dos textos, mas também em relação ao propósito de pesquisar ligado ao processo de formação acadêmica e à educação enquanto um campo de conhecimentos que dialoga com a díade teoria-prática. Foi possível perceber nas falas dos estudantes a existência de alguns mitos ${ }^{3}$ sobre o ato de pesquisar enquanto uma herança platônica, ou seja, pensar, refletir, conhecer é algo inato, e assim sendo, apenas aqueles poucos privilegiados podem pensar o mundo em sua complexidade. Séculos depois das ideias de Platão (427-347 a. C) é que Kant (1724-1804) vem afirmar que o conhecimento não é inato e nem decorre apenas da experiência. Entretanto, a herança cultural grega ainda predomina quando queremos explicar diversos fenômenos do mundo e da vida (SAMPIERI, 2004)

Portanto, existem dificuldades concretas que estão no contexto da vida prática desses estudantes, por exemplo, o cansaço do trabalho, as diversas obrigações assumidas, mas também se dissemina por diversos meios, dentre eles na escola básica, até mesmo de maneira inconsciente ou ingênua, a ideia platônica do conhecimento como algo cindido, ou seja, alguns nascem aptos para atingirem o saber mais elevado (episteme), enquanto outros ficarão

\footnotetext{
${ }^{3}$ ) Mitos são narrativas desenvolvidas por diversos povos (gregos, hindus, chineses, dentre outros) para explicar fatos, crenças sem fundamentos científicos. São válidos para compreendermos elementos culturais de diversos povos.
}

Revista de Administração Educacional, Recife, V. 1 . № 1 . 2017 jan./jun. 2017 p.99-113 
apenas no nível da doxa, da opinião, do superficial. Esta foi um dos problemas que identificamos nesta experiência, ou seja, estudantes se sentindo incapazes de ultrapassarem o senso comum. Neste sentido, o mundo das ideias se sobrepujava em suas falas: "como encontrar um problema para pesquisar, o que vou escrever sobre ele se não tenho ideia de por onde começar?", "Vou inventar problemas? Nesta fala, um dos estudantes ressaltou o valor da capacidade de abstração desvinculado do olhar para o real, ausência de um olhar de indagação para os fenômenos da vida no âmbito da educação. E isto é próprio de percepções ancoradas no platonismo. Como se as ideias viessem antes da percepção dos fenômenos, ou como negava Kant, vindo somente pelo campo da experiência imediata. Um distanciamento que tem permanecido no processo de aprendizagem. As vezes o aluno se perde vivendo o imediato da experiência, em outras vezes que compreender as questões apenas pela via do pensamento.

A fala de outra estudante: "não há mais o que dizer sobre a escola, todo mundo já sabe o que é preciso. Eu vou dizer o que? Observamos nesta fala que o excesso de contato com o cotidiano escolar (principalmente estudantes que atuam como docentes. Neste grupo, onze trabalham como professores contratados) parece tornar o ambiente tão familiar que passa a impressão de não ter mais nada a interrogar. Parece que tudo está evidente, e isto é outro mito a ser desconstruído durante o processo da disciplina Trabalho de Conclusão de Curso.

Por esta razão, alguns estudantes preferem investigar problemas ligados à área da Psicologia, pois para eles, os temas de Gestão, Coordenação, Metodologias, Financiamento da Educação, Formação Continuada, Currículo, Políticas públicas da educação são temas sem interrogações, mas aquilo que está na trama interna do sujeito, em suas percepções, traz potenciais motivações para supostamente entenderem o humano que está na escola, mas, apesar deste desejo, seus conhecimentos não são suficientes para vencerem os obstáculos da compreensão do que se lê e de como se analisa, interpreta no campo da Psicologia.

Dos dezenove participantes, oito deles pensavam em desenvolver pesquisas voltadas para a área da Psicologia. Ao questionar o motivo, seus discursos revelaram: distanciamento com a educação; necessidade de conhecer melhor o ser humano, ambiguidade de sentimentos entre educação e psicologia; fragmentação de saberes nos dois campos de estudos, e algumas idiossincrasias: Psicologia é paixão; lugar de autoconhecimento; emoção é tudo. Dois estudantes pretendiam investigar temas ligados a Educação de Jovens e adultos, mas não conseguiam identificar o problema em si. Os demais (nove) não sabiam qual o tema que desejam pesquisar. 
As experiências desses estudantes com as disciplinas dos estágios também não foram base de apoio fundamental para modificar suas percepções sobre o que pesquisar, o que ler, como desenvolver a escrita. Foi perguntado a eles se disponibilizavam de uma pequena biblioteca pessoal, se organizavam os livros com os temas de suas preferências, se os textos utilizados nas disciplinas contribuíam para entenderem o que gostariam de aprofundar. Apenas quatro estudantes afirmaram desenvolver essa prática, os demais responderam que nem sempre guardavam os textos, e a maioria dos livros vinham dos empréstimos da biblioteca.

Freire (1989, p 08) se reportando as suas memórias de leitura, nos faz compreender a necessidade do empenho pessoal e coletivo:

\begin{abstract}
Continuando neste esforço de "re-ler" momentos fundamentais de experiências de minha infância, de minha adolescência, de minha mocidade, em que a compreensão crítica da importância do ato de ler se veio em mim constituindo através de sua prática, retomo o tempo em que, como aluno do chamado curso ginasial, me experimentei na percepção crítica dos textos que lia em classe, com a colaboração, até hoje recordada, do meu então professor de língua portuguesa. Não eram, porém, aqueles momentos puros exercícios de que resultasse um simples dar-nos conta de uma página escrita diante de nós que devesse ser cadenciada, mecânica e enfadonhamente "soletrada" e realmente lida. Não eram aqueles momentos "lições de leitura", no sentido tradicional desta expressão. Eram momentos em que os textos se ofereciam à nossa inquieta procura.
\end{abstract}

Portanto, a leitura crítica, a escrita argumentativa não se constrói no imediato da situação, e os estudantes compreendiam isto, entretanto, o percurso do ler, do pensar, de problematizar o real que desenvolveram foi, talvez, desorganizado, caótico, embaralhado. $\mathrm{Na}$ experiência de Freire (1989, p.09), "os alunos não tinham que memorizar mecanicamente a descrição do objeto, mas apreender a sua significação profunda. Só apreendendo-a seriam capazes de saber, por isso, de memoriza-la, de fixá -la. [...]" e ainda em sua experiência, "por isso, é que a leitura de um texto, tomado como pura descrição de um objeto é feita no sentido de memorizá-la, nem é real leitura, nem dela portanto resulta o conhecimento do objeto de que o texto fala" (idem, idem).

\title{
A EXPERIÊNCIA EM SALA DE AULA
}

Para além das questões de leitura, os estudantes sentiam dificuldades de comunicar as ideias por escrito. A partir daí, desenvolvemos algumas estratégias para facilitar a elaboração do projeto de pesquisa: a primeira delas foi discutir coletivamente o primeiro mito que conhecer cientificamente seja algo somente para pessoas com inteligência privilegiada, e apresentamos de modo resumido o pensamento platônico, as razões do contexto histórico que 
os conduziram a elaborar uma percepção elitista do ato de pesquisar. Em seguida, dialogamos em torno do segundo mito, que pesquisar nas ciências humanas exige exatidão, busca pela eliminação de erros com um nível de abstração perfeito e que a mensuração empírica é reveladora do conhecimento exato. Trabalhamos o terceiro mito, que é a ideia de não existir mais nada para ser problematizado dentro da escola. Neste sentido, abordamos a singularidade de cada escola, os problemas das políticas educacionais que interferem no modo de se vivenciar avaliação, currículo, didáticas, dentre outros, assim como discutimos a cultura escolar.

A cultura escolar possui uma dinâmica própria, com diversos aspectos obscuros e que necessitam de interrogação, reflexão, partilhas, intervenções, etc. e por fim, abordamos o problema dos fenômenos da experiência, da observação, dos problemas que identificamos sem se deixar levar por crenças, olhando atentamente para as suas manifestações. Este processo é eminentemente humano porque possui uma intencionalidade. Conforme Heidegger (2001), ao olharmos para um determinado fenômeno de modo interrogativo, preocupados com o outro, estabelecemos relacionamento com a nossa condição humana, um estado de abertura para a experiência da afetividade, da compreensão e da expressão. Portanto, a leitura, a escrita argumentativa não acontece no imediato da necessidade de se elaborar um projeto, mas parte da história de vida de cada um, considerando sua experiência escolar, assim como precisamos reconhecer os mitos que existem em nós e limitam a nossa capacidade criativa, a nossa possibilidade de nos tornamos protagonistas de um trabalho científico que agrega diversos valores: desenvolver uma ótica equilibrada de suas potencialidades, ser capaz de organizar as ideias, a escrita argumentativa, entender os princípios da metodologia científica como caminhos para vivenciar o ato de pesquisar, potencializa uma aprendizagem para a solução de problemas, de conflitos, surgimentos de teorias, enfim, pesquisar é uma habilidade humana e contribui para o aprimoramento de diversas capacidades.

No transcorrer da experiência, tentamos facilitar a construção de alguns conceitos que os estudantes consideravam difíceis de entender: Crítica, Análise, Síntese e Concepção. A escolha destas quatro categorias teve origem na fala dos estudantes, uma vez que a maioria das atividades acadêmicas desenvolvidas ao longo do curso solicitavam deles este conjunto de palavras. Para realizar a tentativa de ajuda-los a se relacionarem com a leitura e com a escrita acadêmica propomos um exercício de procurar construir o significado dos quatro conceitos acima a partir da leitura de um dos livros de Paulo Freire: A importância do ato de ler elou 
Educação e Mudança, em seguida deveriam elaborar suas compreensões do vocabulário que consideram complexo para entenderem um texto científico, uma tarefa acadêmica ou um projeto de pesquisa: os conceitos de crítica, análise, síntese, concepção, tomando como ponto de partida a leitura que fizeram dos textos de Freire, pois tais palavras, segundo os estudantes não estão claras. O entendimento coletivo foi construído e estes conceitos foram descritos conforme demonstra o quadro 02 .

Quadro 02 - Conceitos elaborados coletivamente a partir das compreensões dos textos de Paulo Freire e de experiências dos estudantes

\begin{tabular}{|c|c|}
\hline Unidade vocabular & Significado construído \\
\hline Crítica & $\begin{array}{l}\text { A crítica é um movimento do pensamento e que está } \\
\text { ligado ao modo de ver as coisas sem ingenuidade, } \\
\text { pois tudo tem conexão com o que acontece na } \\
\text { sociedade, na história, na cultura. Não se constrói } \\
\text { uma crítica forte sem conhecer os problemas da } \\
\text { realidade. Nada é neutro e toda crítica traz uma } \\
\text { posição política. A escrita crítica é uma escrita que } \\
\text { olhou antes para a realidade e daí dialoga com ela. É } \\
\text { uma coisa de conexão com vários fatores que a } \\
\text { pessoa precisa questionar. É, a crítica só acontece se } \\
\text { você questionar e for em busca de respostas. }\end{array}$ \\
\hline Análise & $\begin{array}{l}\text { A análise parece com a crítica, mas ao mesmo tempo } \\
\text { é diferente porque ela tem a função de examinar uma } \\
\text { afirmação de maneira detalhada e assim se } \\
\text { compreende melhor o problema, ele fica mais claro e } \\
\text { daí pode elaborar a crítica. Ex: Se alguém disser que } \\
\text { a educação provoca mudanças, podemos analisar que } \\
\text { tipo de mudanças a educação provocou ou provoca. } \\
\text { Como a mudança acontece, porque acontece, quem } \\
\text { provoca a mudança, etc. Quando entendemos essas } \\
\text { questões aí podemos elaborar a crítica fundamentada } \\
\text { com os argumentos que a leitura facilita, e a } \\
\text { experiência também. }\end{array}$ \\
\hline
\end{tabular}

Revista de Administração Educacional, Recife, V. 1 . № 1 . 2017 jan./jun. 2017 p.99-113 


\begin{tabular}{|c|l|}
\hline Síntese & \begin{tabular}{l} 
É a parte que unimos todas as análises, as críticas e \\
elaboramos um texto inteiro, sem perder a ideia \\
central, demonstrando o ponto de partida, as análises \\
com sentido, com compreensão, podemos incluir as \\
críticas para criar um tecido inteiro, um texto com \\
coerência. \\
\hline Concepção
\end{tabular} $\begin{array}{l}\text { É a capacidade de gerar uma ideia. Quando um } \\
\text { professor pede que se elabore uma concepção, ele } \\
\text { está querendo que o aluno gere sua interpretação do } \\
\text { que foi lido, mas sem ingenuidade, isto é, } \\
\text { percebendo que a ideia está ligada a uma } \\
\text { determinada teoria, um aspecto relevante que foi } \\
\text { trabalhado em sala de aula ou que esteja ligado a } \\
\text { outras leituras que o aluno pode articular e ser capaz } \\
\text { de produzir sua própria ideia. Nada tem uma } \\
\text { concepção definitiva, tudo é construído dependendo } \\
\text { do tempo, da história, da cultura e das condições de } \\
\text { vida das pessoas. Por isto não existe só uma } \\
\text { concepção das coisas. Vida para a biologia é uma } \\
\text { coisa, para a religião pode ser outra. E dentro dessas } \\
\text { ciências tem muita variedade de concepção. }\end{array}$ \\
\hline
\end{tabular}

Esta atividade introdutória da disciplina foi vivenciada em três encontros, cada um com quatro horas de duração. Embora o exercício tenha sido individual em um primeiro momento, mas, em seguida, houve a discussão coletiva que ajudou na reconstrução do texto de cada um. Após este momento, as duplas que estavam elaborando o projeto de pesquisa se uniram para a reelaboração das ideias. Em seguida, solicitamos que fizessem o exercício de escolher três frases do livro Educação e Mudança (2008), da autoria de Freire e utilizá-las para refletirem em torno de fenômenos da realidade educacional.

A primeira frase escolhida foi "O Compromisso do Profissional com a Sociedade" (p.15). Os participantes da experiência realçaram a necessidade do educador não se perceber como alguém que tem obrigação apenas com a escola que ensina, mas deve ter um propósito 
mais profundo que é ajudar o aluno a conhecer a sua história, a se ver como alguém que pode modificar coletivamente a história. A segunda frase selecionada pelos estudantes: "Comprometer-se com a desumanização é assumi-la e, inexoravelmente, desumanizar-se também" (p.19). Revelaram preocupações com o modelo educacional que desumaniza o outro, que extrai apenas conteúdos, que torna o outro um memorizador de assuntos, que não permite a criatividade, que não tem amorosidade para com o ser humano. Porém, ressaltaram que muitas vezes as condições de trabalho dos professores são desumanas, por isto é difícil lutar contra a desumanização.

Neste momento, desenvolvemos uma reflexão sobre o trabalho docente, as condições exigidas para que seja considerado um bom professor, a exigência de uma matriz curricular calcada em conteúdos distante da vida real, e também foi abordada a questão da pressa que se tem para o aluno aprender rápido e sair logo da escola para dar vez ao outro. Neste processo de reflexão fomos compreendendo quantos problemas há dentro das escolas que pedem por uma investigação, um olhar interrogativo, e isto foi modificando essa percepção de que não existe mais o que se estudar no interior das escolas públicas.

Por último, a frase selecionada pelos estudantes, foi: "Daí o homem alienado, inseguro e frustrado, ficar mais na forma que no conteúdo; ver as coisas mais na superfície que em seu interior" (p. 25). Os estudantes se identificaram com esta frase porque se percebiam frágeis em relação aos conhecimentos, e sentiam que ainda dicotomizavam demais os conhecimentos, se percebiam com dificuldades para mover as ideias, a consciência, desalienar-se, olhar para os fenômenos com mais profundidade. Ao término da experiência, todos avaliaram a dinâmica a partir dos seguintes aspectos:

1 - A dinâmica utilizada contribuiu para que entendessem as crenças limitantes sobre o ato de pesquisar;

2 - Reconheciam a frágil organização de estudos pessoais, da elaboração de resumos, resenhas, de tentativas de escritas, de procurar os docentes nos momentos de dúvidas;

3 - Expressaram que tinham muitas expectativas em torno da figura do professor e baixa compreensão da importância do seu papel, enquanto estudantes, no próprio processo de aprendizagem, o que dificultava avançar na construção do saber; 
4 - Perceberam que possuem potencial, que são capazes, mas não se viam no lugar de dialogar em sala de aula porque muitas vezes não leram os testes, de modo, que as dificuldades vieram pela não leitura atenta do que era preciso entender;

5 - Entenderam que o desinteresse pela escola os afastava de alguns textos, pois não se viam como professores que poderiam intervir de maneira eficaz no processo educativo, daí a necessidade de ir em busca de temáticas diferentes sobre o ser humano.

6 - Reconheceram o medo de expressar as ideias por se sentirem inseguros e com medo da avaliação;

7 - Afirmaram que agiam pela lei do menor esforço. Se condicionaram a concordar, na maioria das vezes, com os textos para não se dar ao trabalho de pensar e questionar;

8 - Entendem que precisam modificar este quadro de comportamentos para retomar o próprio processo de construção de conhecimentos e saberes.

A partir desses procedimentos e avaliações, a disciplina transcorreu buscando construir interfaces, diálogos entre os temas para pesquisa, o processo de pesquisar enquanto ato de formação permanente e os componentes necessários para estruturar um projeto de pesquisa.

\section{CONSIDERAÇÕES FINAIS}

Os capítulos dos livros "A importância do ato de ler" e "Educação e Mudança" serviram como meio norteador para o estudo individual e coletivo. A atividade contribuiu para que os estudantes elaborassem algumas percepções que para eles são importantes no ato de pesquisar. O propósito foi dialogar com as dificuldades que apresentaram e ao mesmo tempo, desenvolver uma dinâmica facilitadora do processo de desenvolvimento de leituras críticas e escritas mais profundas.

Outro aspecto importante, abordado durante este processo introdutório foi a compreensão do papel que cada um exerce no processo de pesquisar. A pesquisa não se reduz a um momento para os estudantes finalizarem sua formação acadêmica, mas está conectada a modificação das percepções destes sobre o fenômeno educativo, que ao mesmo tempo está ligado a uma rede de situações, de maneira que possam enfrentar os problemas, intervindo de modo politizado, ético, sensível e científico.

Revista de Administração Educacional, Recife, V. 1 . No 1 . 2017 jan./jun. 2017 p.99-113 
Ao término da atividade proposta foi possível perceber que os estudantes que participaram da experiência foram capazes de perceber suas próprias fragilidades e crenças limitantes, assim como se viram mais capazes, mais equilibrados emocionalmente para enfrentarem a escrita do projeto de pesquisa, e, posteriormente praticarem a pesquisa de campo. Entenderam que o processo de pesquisar não estava fora do seu contexto de vida, uma vez que a pesquisa não poderia surgir do nada, mas da observação criteriosa, intencional dos problemas que conseguiam identificar na educação. A experiência não solucionou todos os problemas, não eliminou as angústias, mas melhorou a autoestima dos participantes. Pesquisar continuou a ser um desafio a ser enfrentado. Ao término da experiência, colocamos a seguinte frase para gerar mais incentivo aos estudos, à organização das ideias e dos estudos:

Cada um, no fundo, é gênio, na medida em que existe uma vez e lança um olhar inteiramente novo sobre as coisas. Multiplica a natureza, cria por este novo olhar. Salvem seu gênio. É o que é preciso gritar para as pessoas. Liberem-no, façam o possível para libertá-lo (NIETZSCHE, 2000, p. 34)

A frase acima foi bastante aplaudida, pois o motivo não era discutir se o filósofo Nietzsche estava certo ou errado, mas o de provocar, de brotar o nosso olhar questionador sobre o mundo e que Nietzsche chama de "gênio". Compartilhar os medos, as dúvidas em sala de aula, gerar trocas com os diversos grupos de modo natural, com comprometimento, para relembrar Paulo Freire. É uma desterritorialização insuportável não ser reconhecido pelo outro naquilo que somos enquanto humanos, por isto a necessidade de mostrarmos nossos fragmentos, que, na maioria das vezes não é muito diferente daquele que está sentado perto de mim. E assim foi feito na medida do possível, entender os fragmentos trazidos e tentar recompor a partir do tempo e das condições permitidas pela disciplina.

Esta experiência em sala de aula, simples, talvez muito mais de escuta e de trocas, contribuiu para a construção dos projetos de Trabalho de Conclusão de Curso com mais clareza para os estudantes, facilitadas pelo acompanhamento dos orientadores dos projetos, assim como para a compreensão do significado do ato de pesquisar enquanto arte de elaborar respostas para problemas identificados no contexto da vida, sem perder a noção da importância do rigor que a ciência de pesquisar necessita.

\section{REFERÊNCIAS}

CAMPBELL, Joseph. As Máscaras de Deus. São Paulo: Palas Athena, 1995.

Revista de Administração Educacional, Recife, V. 1 . № 1 . 2017 jan./jun. 2017 p.99-113 
FREIRE, Paulo. Educação e Mudança. Rio de Janeiro: Paz e Terra, 2008.

FREIRE, Paulo. A importância do ato de ler em três artigos que se completam. São Paulo: Cortez, 1989.

HEIDEGGER, Martim. Ser e Tempo. Vol I. São Paulo: Zahar, 2001

NIETZSCHE, Friederich. Fragmentos Póstumos. São Paulo: Zahar, 2000.

SAMPIERE, Roberto. Metodologia de Pesquisa. Porto Alegre: Penso, 2004. 